\title{
USO E CONSUMO \\ DE RECURSOS ENERXÉTICOS EN GALIZA NO SÉCULO XX
}

Xoán R. Doldán-García

Universidade de Santiago de Compostela 

Unha das dificultades principais á hora de levar a cabo unha análise cuantitativa do uso e consumo dos recursos enerxéticos en Galiza ao longo do último século provén da enorme dispersión da información estatística. Non existe unha única fonte de datos, nin sequera unha que abranga a maior parte do período. Tampouco podemos outorgar o mesmo rigor ás distintas fontes dispoñíbeis, nin sequera a mesma metodoloxía de recollida de datos. Outro problema adicional ten que ver co feito de que a información do Estado español non sempre está segregada por provincias. Con todo, e considerando todas estas eivas de partida, dispoñemos dalgúns estudos especialmente interesantes para realizarmos a dita reconstrución histórica (Bartolomé 2007; Carmona 2016; Carreras / Tafunell, 2005; Martínez / Mirás / Lindoso 2009; Comisión para el Estudio de Necesidades y Recursos Energéticos 1961) e, sobre todo a partir dos anos cincuenta, a Estadística de la Industria de la Energía Eléctrica ou, a partir dos anos oitenta, algunhas fontes realizadas xa desde Galiza (GESTENGA 1993; INEGA 2001 a 2017). Tamén cómpre indicar que a maior parte da información estatística se concentrou na utilización de recursos enerxéticos para a obtención de electricidade e, en menor medida, para a obtención de calor. Datos específicos para o uso de combustíbeis fósiles por provincias son máis tardíos e, no caso de Galiza, comezan a ser relevantes a partir dos anos sesenta. Outros estudos centrados no caso galego servíronos para completar a serie estatística que utilizaremos a continuación (Sequeiros 1986).

A serie reconstruída permítenos ver a evolución do consumo de enerxía primaria, é dicir, dos recursos antes da súa transformación, desde comezos do século XX á actualidade (gráfico 1). Non dispoñemos de datos para o período 1935-1940. A partir dos anos oitenta tomouse a decisión de contar exclusivamente coa información dos Balances Enerxéticos de Galiza, que só aparecerán 
como publicación con periodicidade anual e cunha información máis completa a partir do 2000 .

Gráfico 1. Evolución da enerxía primaria transformada. Galiza, 1901-2015 (ktep) por fontes

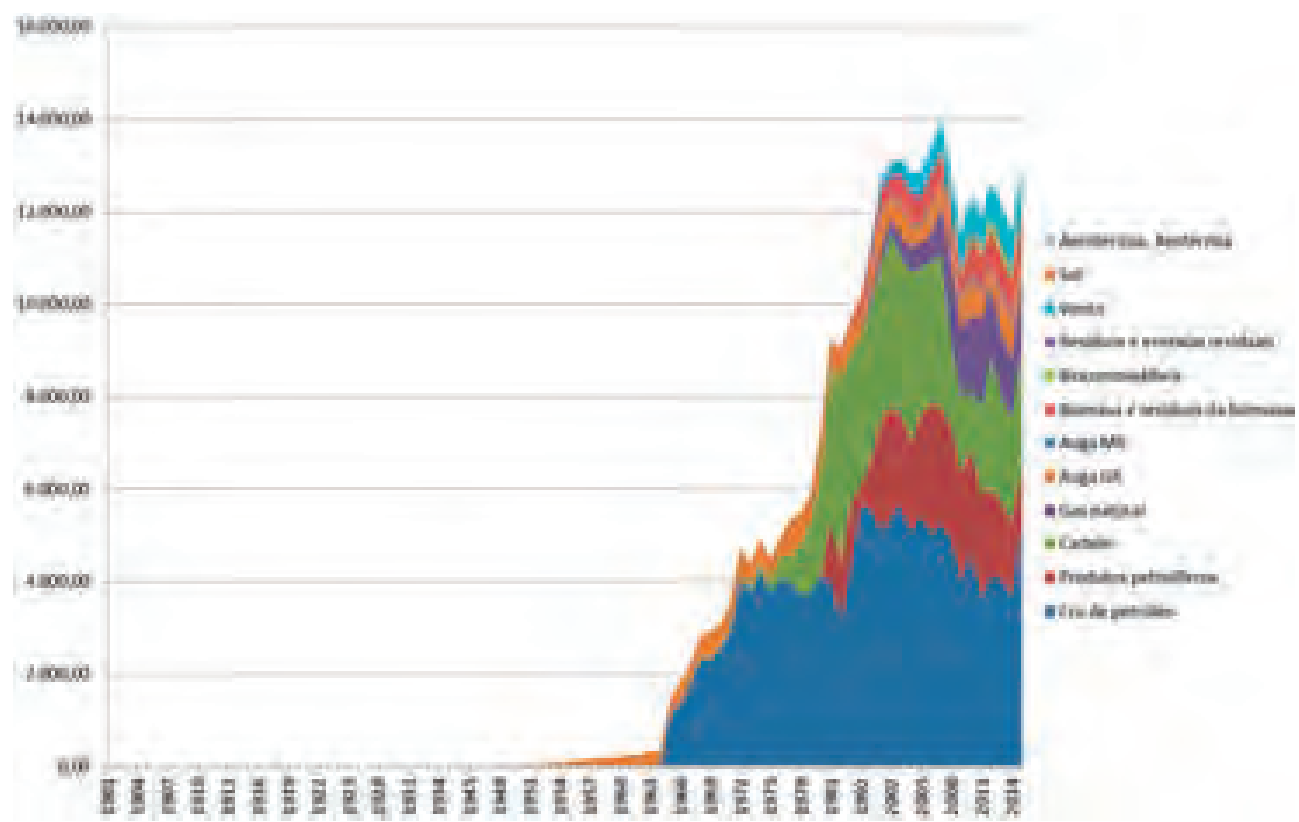

Fonte: Doldán (2017)* Elaboración propia a partir de Bartolomé (2007), Carmona (2016), Carreras / Tafunell (2005), Consellería de Industria e Enerxía (1984), Consellería de Industria, Comercio e Turismo (1988), Estadistica de la Energía Eléctrica (varios anos), GESTENGA (1993), INEGA (2001, 2003a, 2003b, 2004, 2006, 2007, 2008, 2010a, 2010b, 2011, 2012, 2014, 2017a, 2017b e 2017c), Martínez / Mirás / Lindoso (2009), Sequeiros (1986).

En calquera caso, entendemos que a información é o suficientemente válida para ver esta evolución. Ao observarmos os gráficos pode dar a impresión de que antes dos anos corenta non existen datos estatísticos ou que o uso de enerxía primaria en Galiza é case nulo, mais o certo é que ao representar todo o período nun mesmo gráfico, e dado o fortísimo ascenso do consumo enerxético nos anos sesenta, a primeira metade do século parece insignificante. Este gran salto come- 
za a xestarse nos cincuenta, pero será nas décadas posteriores cando se acabe de materializar.

Se consideramos o consumo global, á marxe das diferentes tipoloxías de enerxía, o crecemento exponencial nas últimas décadas é evidente. Estes datos mesmo poderían ser corrixidos á alza coa inclusión do consumo de biomasa, normalmente ausente de moitas estatísticas enerxéticas cando os usos se cinxen a aqueles máis tradicionais no ámbito doméstico e non industrial.

O primeiro cambio significativo ten lugar en 1964 coa apertura da refinaría da Coruña, que obrigará á importación de elevadas cantidades de petróleo cru para refinar. Con anterioridade, nos anos cincuenta, fora crecendo o uso de enerxía hidráulica, para o que foi preciso a construción dun número crecente de novos encoros. Grazas a iso xa tiña mudado, en parte, a estrutura enerxética do país, que, ata ese momento, estaba centrada tanto en usos hidráulicos como de carbón, sendo este practicamente todo el importado. Nos anos cincuenta comeza, ademais, a utilización de carbón de orixe galega a partir da explotación das minas das Pontes. Con todo, haberá que agardar ata os anos setenta, cando se instale a central térmica das Pontes, para ver un uso relevante do carbón galego, máis aínda cando neses mesmos anos se poña en marcha outra central térmica en Meirama, que utilizará os lignitos extraídos nunha mina a pé da central.

Se atendemos á evolución por tipos, vemos que en case todos eles ten lugar ese gran salto a partir dos anos sesenta.

No caso da enerxía hidráulica (gráfico 2), ese salto xa se observa nos anos cincuenta, porén a senda de crecemento é máis ríxida que nas outras tipoloxías. A partir dos setenta, o uso desta enerxía estáncase porque non se construíron daquela grandes encoros e, por outra parte, debido a que a dispoñibilidade desta enerxía ten unha certa dependencia dos ciclos hidráulicos.

En canto ao carbón (gráfico 3), cómpre destacar dous fitos, un nos anos cincuenta coa explotación do carbón das Pontes, destinado fundamentalmente á fabricación de fertilizantes, e outro nos setenta co fortísimo incremento do seu uso coa explotación das minas das Pontes e Meirama para a obtención de 
Gráfico 2. Evolución da produción de enerxía hidráulica. Galiza, 1901-2015 (ktep)

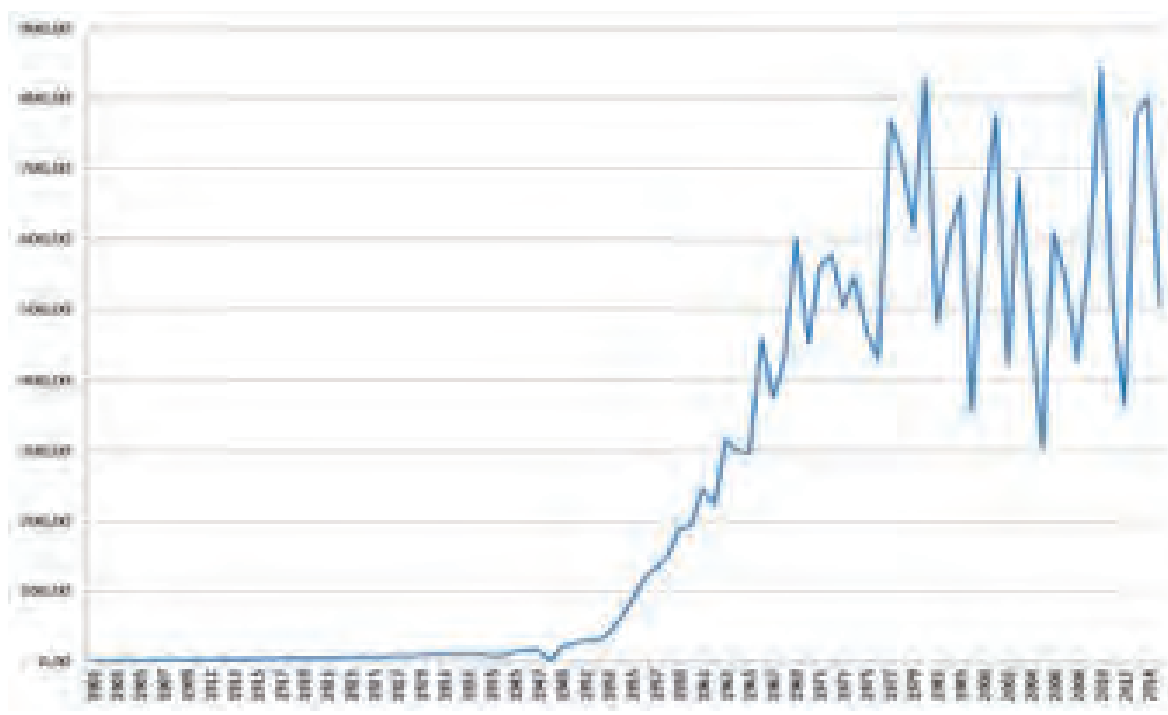

Fonte: Doldán (2017)*.

Gráfico 3. Evolución do carbón transformado. Galiza, 1901-2015 (ktep)

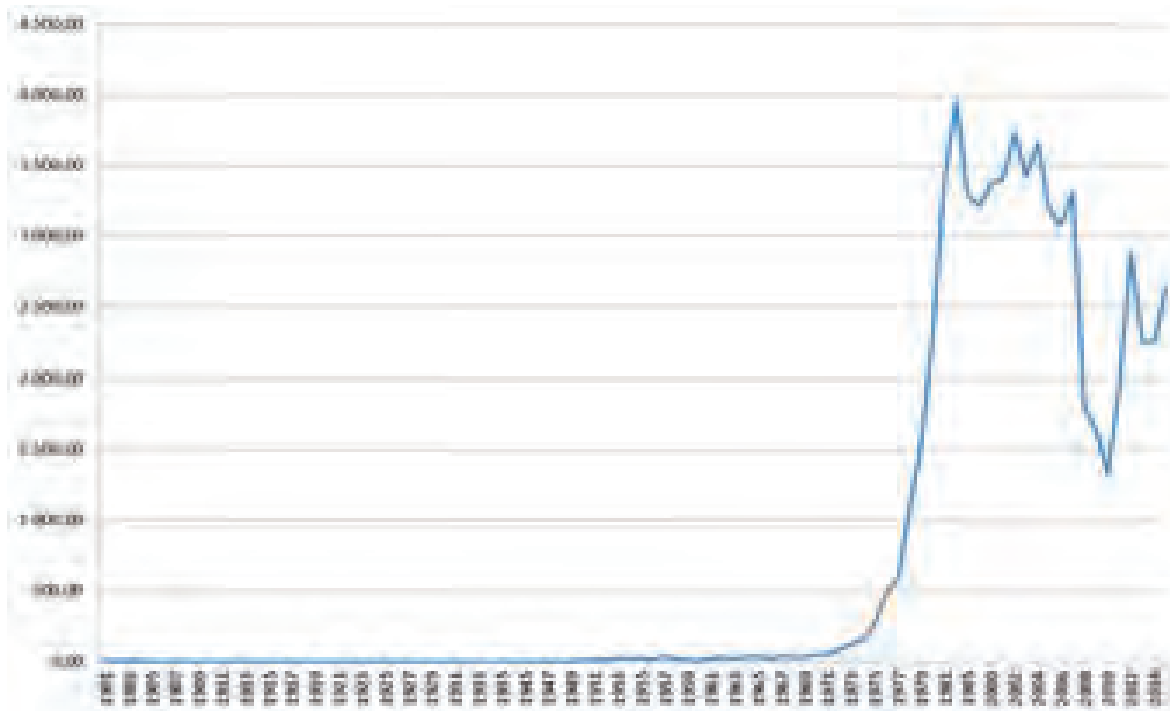

Fonte: Doldán (2017)*. 
electricidade. A partir de aí, e durante uns 25 anos, o carbón que se vai utilizar é fundamentalmente de orixe galega. Ao remate dese período, e segundo se van esgotando estes xacementos, comeza a crecer o uso de carbón importado. Desde 2009 todo o carbón utilizado en Galiza procede da importación, e isto vai causar que se reduzan os usos de enerxía de orixe autóctona.

O gas natural (gráfico 4) é un combustíbel fósil de uso máis recente en Galiza. A extensión dos gasodutos peninsulares ata este territorio e a construción da planta regasificadora de Mugardos facilitaron un uso crecente deste. Todo o gas natural procede da importación e o rápido e forte incremento débese entender, en gran medida, polo seu papel como substituto do carbón para a xeración de electricidade - unha vez esgotado o carbón galego- ademais de por usos domésticos e industriais cada vez maiores.

Gráfico 4. Evolución do gas natural procesado. Galiza, 1901-2015 (ktep)

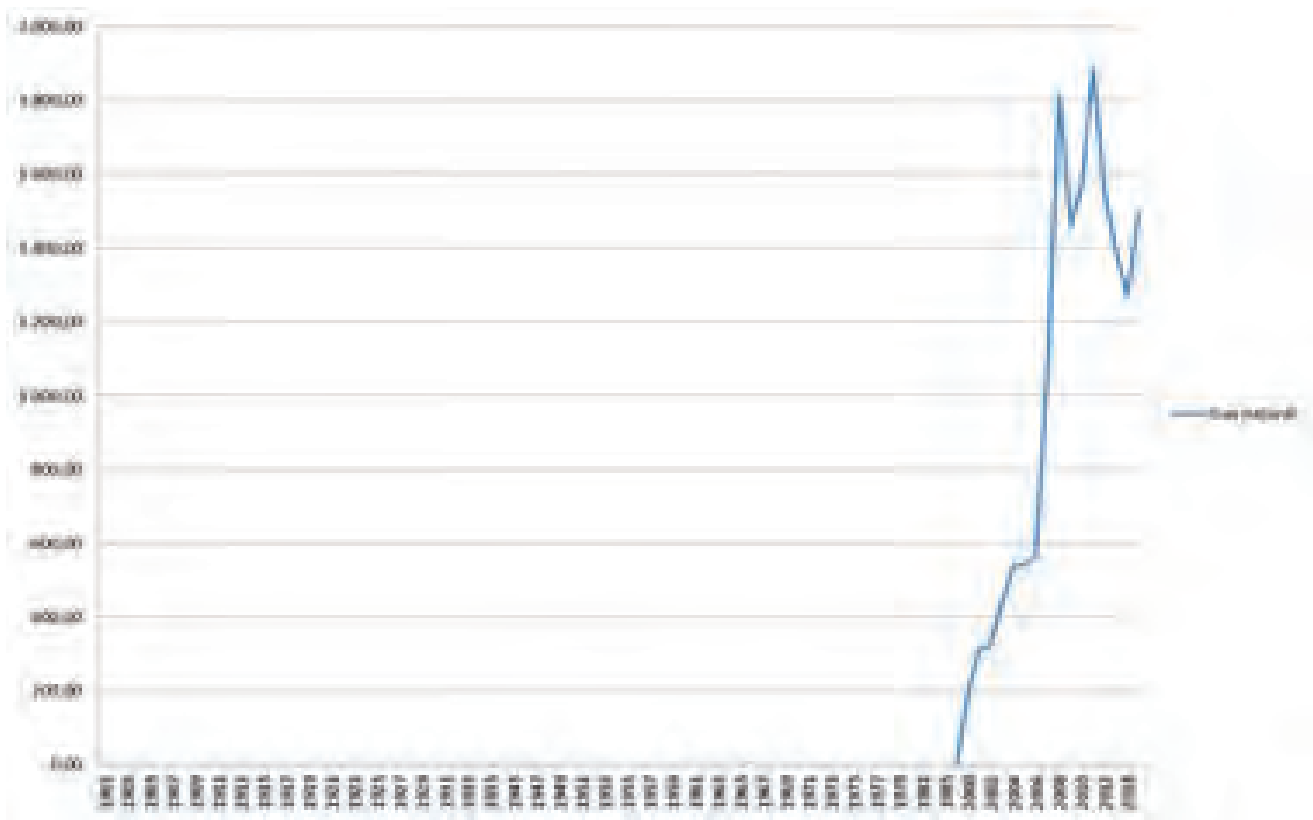

Fonte: Doldán (2017)*. 
No caso do petróleo cru (gráfico 5), todo el é importado. O uso comeza a ser relevante a partir de 1964 coa posta en marcha da refinaría da Coruña. Unha vez transformado, este petróleo en forma de diversos combustíbeis vai ter un consumo final tanto dentro de Galiza coma no resto do Estado español. Debemos lembrar que a da Coruña é actualmente unha das nove refinarías que hai en España, cunha capacidade de refino que supón un $9 \%$ do total no Estado. En 1964 era a cuarta construída no país e a terceira en capacidade de refino (alcanzaba un $22 \%$ da capacidade total naquel ano).

Gráfico 5. Evolución do cru de petróleo procesado. Galiza, 1901-2015 (ktep)

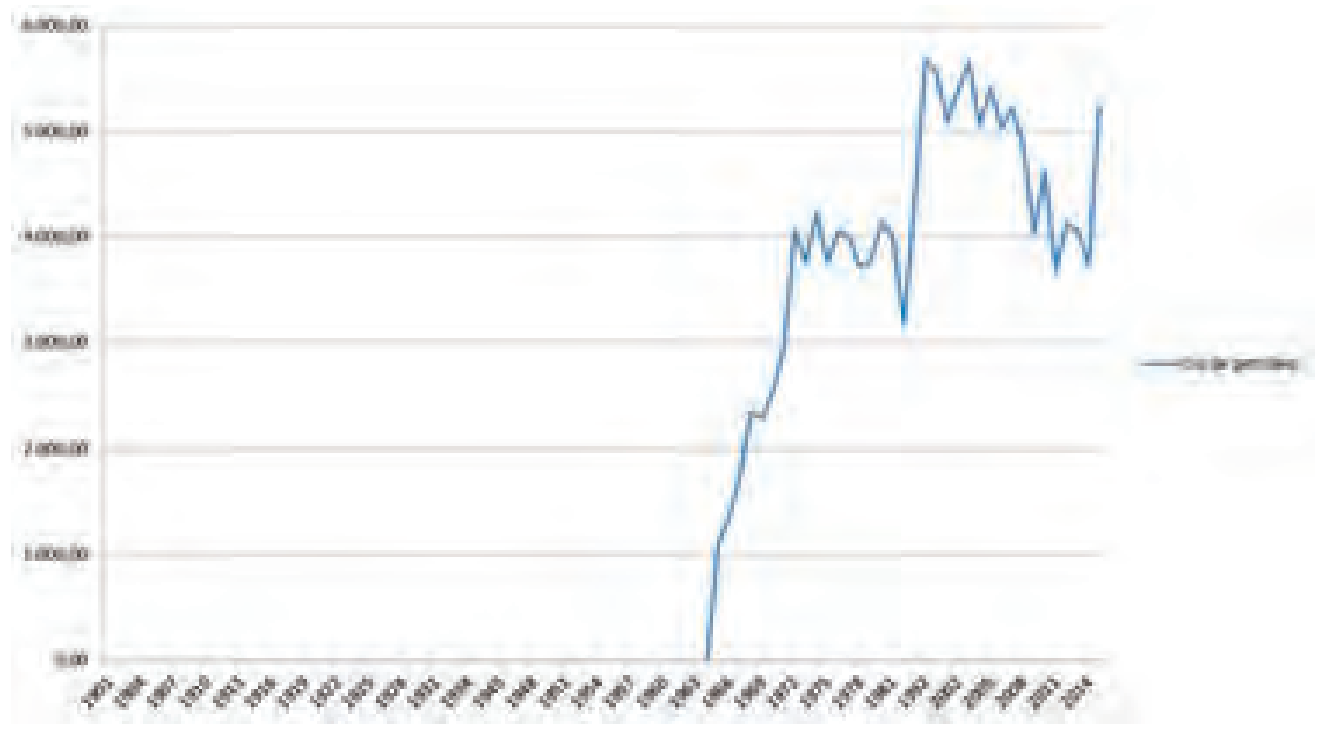

Fonte: Doldán (2017)*.

A incidencia da enerxía eólica (gráfico 6) na estrutura enerxética galega non se percibirá ata o século XXI. A razón podemos atopala nos cambios normativos favorábeis ao desenvolvemento deste tipo de enerxía e no feito de que a demanda de enerxía, en particular a eléctrica, estaba a ser cada vez maior. Esta fonte enerxética serviu para atender esta demanda crecente, ao tempo que se permitía manter a capacidade de exportación de electricidade desde Galiza. 
Gráfico 6. Evolución da xeración de enerxía eólica. Galiza, 1901-2015 (ktep)

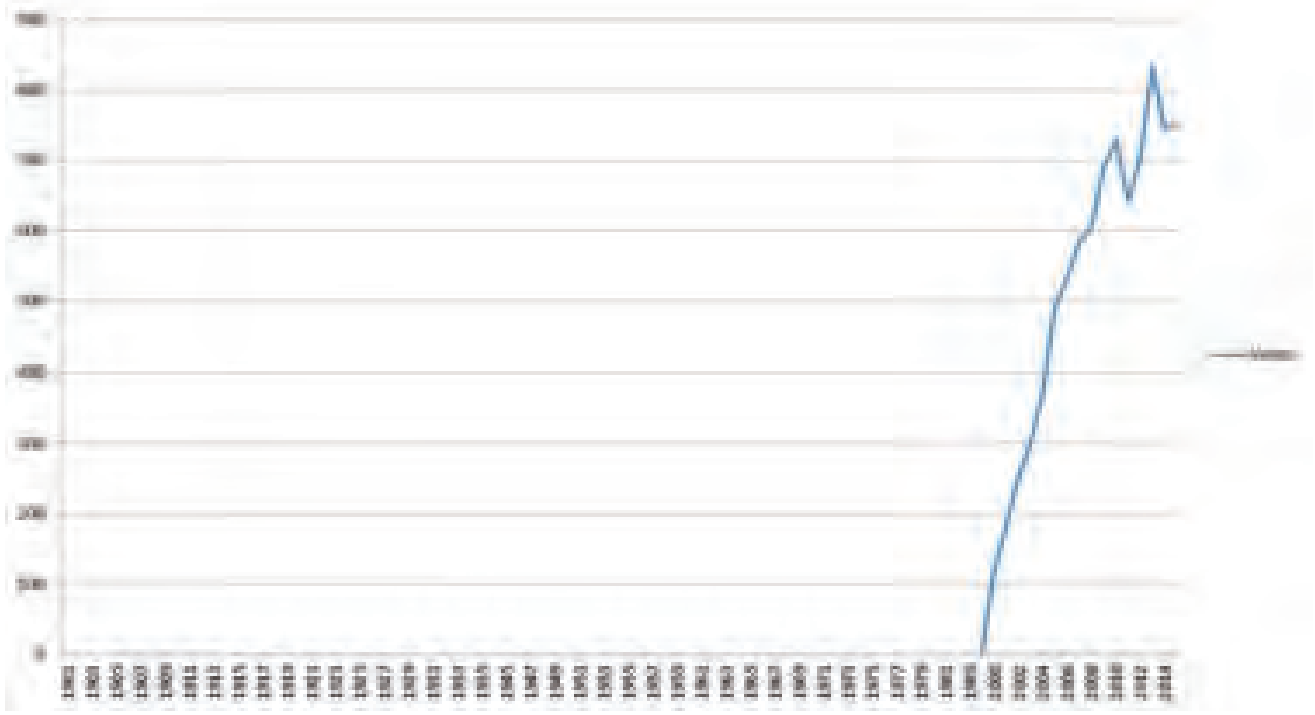

Fonte: Doldán (2017)*.

A panorámica que acabamos de describir sérvenos para destacar varios aspectos que caracterizan o sistema enerxético galego desde os anos setenta (gráfico 7). Un deles é o peso maioritario das enerxías fósiles (carbón, gas natural e petróleo), que na actualidade proceden integramente da importación. En segundo lugar estarían as enerxías renovábeis, que, agás os biocombustíbeis (para os que se importa materia prima), son de orixe autóctona. A presenza das renovábeis é maior do que se pode observar no caso español ou na Unión Europea. A pesar disto a nosa base enerxética segue a ser fundamentalmente fósil.

Vendo a orixe da enerxía primaria desde os anos oitenta en Galiza (gráfico 8), é evidente a redución da presenza de enerxía de orixe galega. Paradoxalmente, nestes anos houbo un esforzo considerábel por instalar centrais de enerxía renovábel (eólica e outras) que aproveitasen en maior medida os recursos galegos. Con todo, o esgotamento do carbón galego non se compensou coa capacidade de xeración destas novas centrais. Pola contra, a enerxía importada foi gañando peso paulatinamente ata converterse na orixe principal. 
Gráfico 7. Evolución dos distintos tipos de enerxía primaria. Galiza, 1965-2015 (ktep)

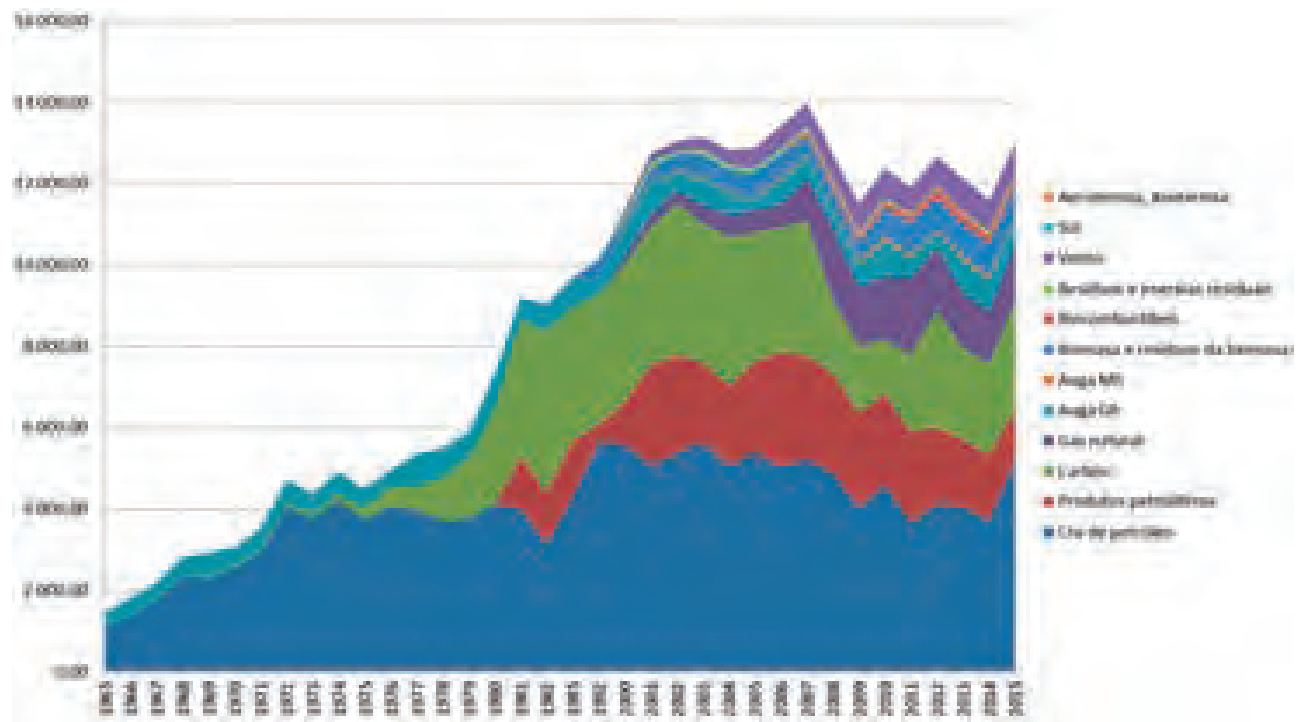

Fonte: Doldán (2017)*.

Gráfico 8. Evolución da enerxía primaria segundo a súa orixe. Galiza, 1981-2015 (ktep)

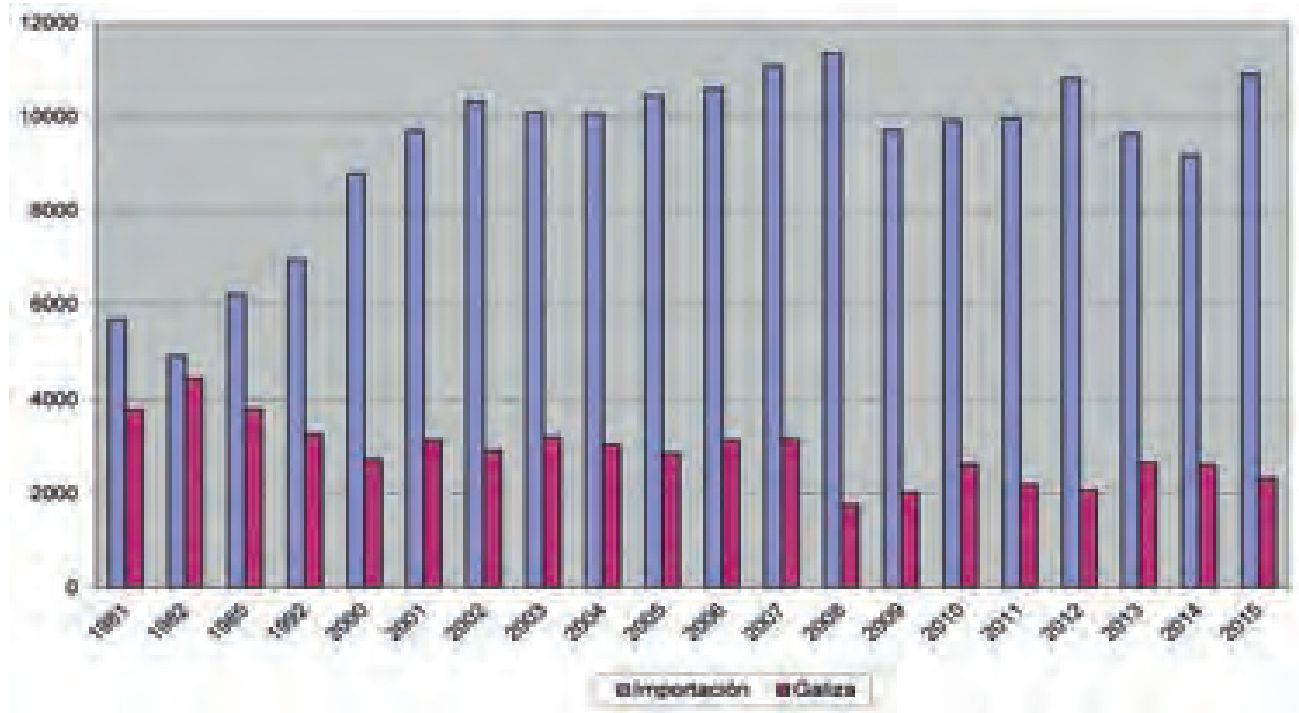

Fonte: Doldán (2017)*. 
Sendo un cambio significativo, non é a primeira vez que sucede isto en Galiza. Xa nos anos sesenta acontecera algo semellante. A instalación da refinaría dera lugar a unha importación masiva de petróleo cru e isto provocou que as fontes autóctonas pasaran a ter un peso relativo menor.

Se comparamos a evolución da enerxía primaria fronte ás exportacións, tendo en conta que unha boa parte da materia prima aquí transformada ten como destino a exportación. Estas importacións de enerxía primaria mostran unha dependencia enerxética crecente. Porén, existe unha crenza xeneralizada dunha sobreabundancia enerxética en Galiza ao sermos quen de exportar grandes cantidades de enerxía transformada. Mais o certo é que esta capacidade de exportación se nutre da importación masiva de enerxía primaria (gráfico 9). Por iso, aínda caendo a obtención de enerxía primaria propia, Galiza foi capaz de manter esa capacidade de exportación e mesmo estamos exportando máis enerxía da obtida con recursos propios.

Gráfico 9. Evolución da enerxía primaria galega e das exportacións de enerxía.

Galiza, 1981-2015 (ktep)

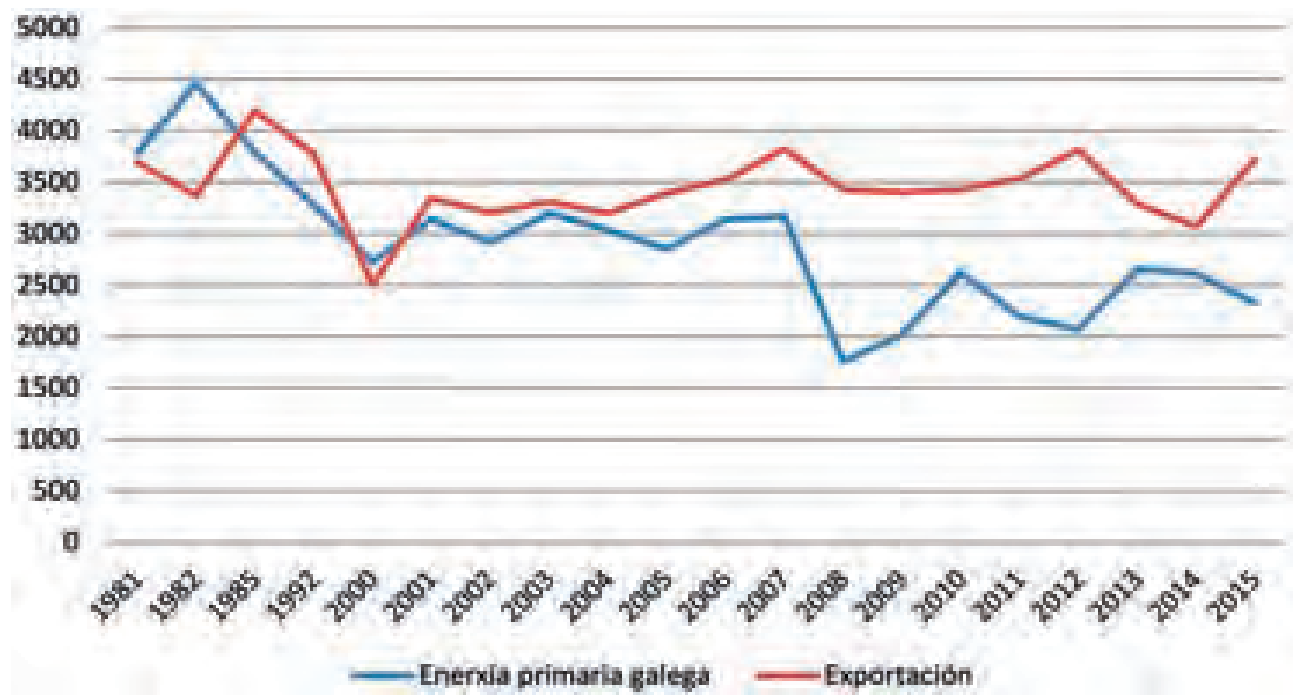

Fonte: Doldán (2017)*. 
Por outra parte, hai un elevado crecemento da demanda interna de enerxía en Galiza a partir dos anos setenta e oitenta, non só polo consumo doméstico senón sobre todo polo consumo industrial. Cando nos anos oitenta a factoría de transformación de alúmina e aluminio na costa de Lugo comeza a funcionar a pleno rendemento, este sector industrial suporá a duplicación do consumo eléctrico interno galego. Esta alteración extrema do consumo interno non podería terse dado de non ser porque pouco antes as centrais térmicas das Pontes e Meirama ampliaron a capacidade de xeración de electricidade ao mobilizaren un recurso galego como era o carbón. Esas dúas centrais permitirán, ademais, manter case intactas as exportacións de electricidade desde Galiza. Hoxe en día a situación é moi diferente; é preciso importar carbón e gas natural para conseguir o mesmo efecto (incluso para cubrir parte do consumo interno de electricidade) (gráfico 10).

Parte da idea de sobreabundancia que mencionamos ten que ver especificamente coa produción de electricidade, ou mesmo co feito de que se exporten derivados de petróleo, gas natural manufacturado ou biocombustíbeis, ignorándose a mudanza radical do sistema enerxético galego tanto na esfera da produción como do consumo. Confúndese a capacidade xigantesca de transformación da enerxía galega con relación aos recursos enerxéticos propios ou ao consumo interno, coa circunstancia de que durante décadas se manteña case intacto o volume de exportación de enerxía transformada.

Se nos fixamos especificamente nos usos eléctricos desde os anos 50 (gráfico 11), vemos que a electricidade consumida foi aumentando moito máis que a electricidade exportada. Que unha e outra non evolucionen en senso contrario, é dicir, que un maior consumo interno non reduza a capacidade de exportación, é debido ás importacións de enerxía primaria ás que nos temos referido. O salto dos anos oitenta que se observa no gráfico vén motivado porque naquela altura había unha orientación cara á xeración en centrais térmicas de carbón. Nos últimos anos a electricidade consumida internamente chega a superar á exportada, cando noutras épocas sucedía o contrario. 
Gráfico 10. Evolución do consumo interno galego e das exportacións de enerxía.

Galiza, 1981-2015 (ktep)

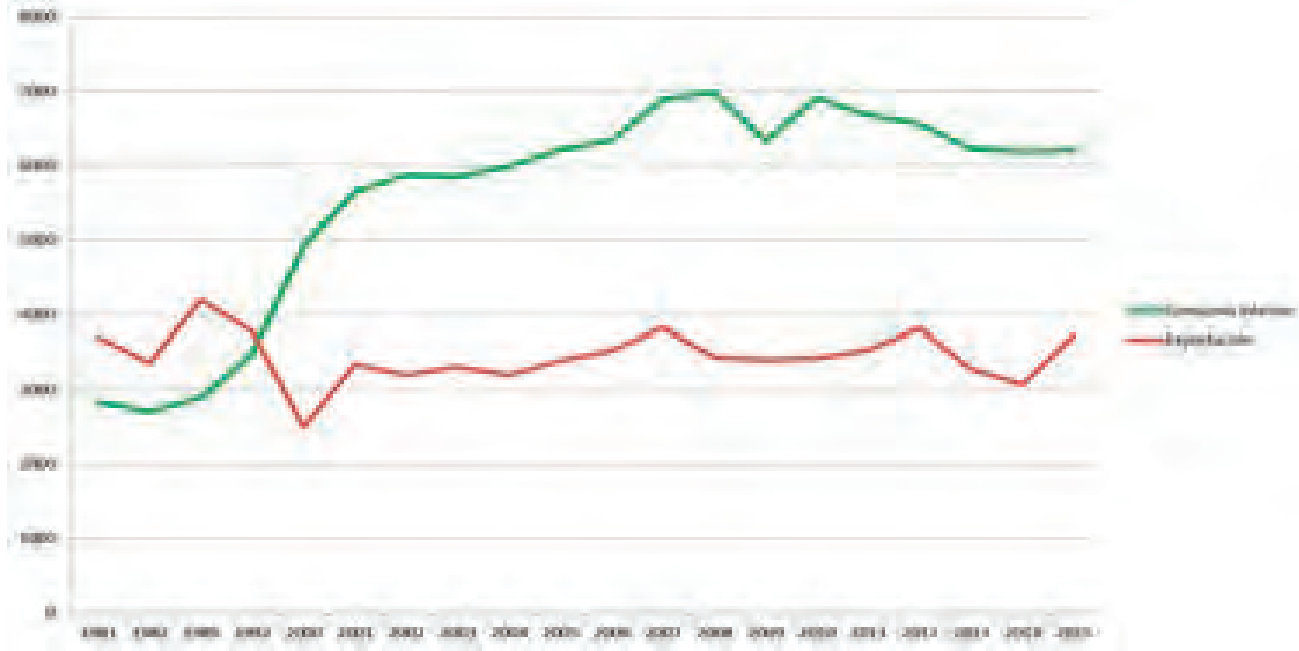

Fonte: Doldán (2017)*.

Gráfico 11. Evolución da electricidade consumida en Galiza e da exportada. Galiza, 1950-2015 (ktep)

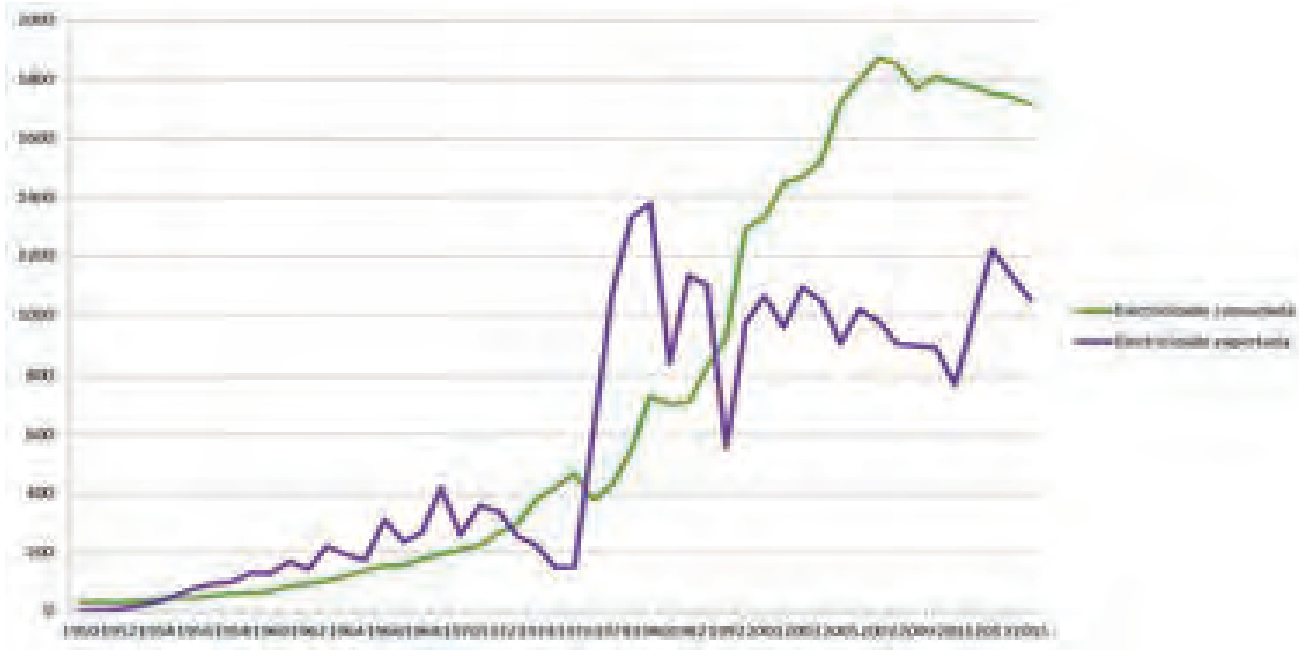

Fonte: Doldán (2017)*. 
A modo de conclusión e resumo poderiamos dicir que, desde comezos do século XX, os usos enerxéticos en Galiza pasaron polas seguintes fases:

- Primeira metade do século Xx: os usos enerxéticos estaban centrados no consumo de biomasa para usos domésticos e no de carbón importado e de enerxía hidráulica. Nesta etapa os consumos enerxéticos totais e per cápita son relativamente baixos.

- Anos 50: ten lugar a construción de grandes encoros, o que fai aumentar o peso da enerxía hidráulica e da xeración de electricidade. O consumo enerxético interno elévase e comeza a haber exportacións significativas de electricidade cara ao resto do Estado.

- Anos 60: comeza a importación cada vez maior de petróleo cru para ao refinado en Galiza. Pola súa vez vaise producir un aumento do consumo interno de derivados do petróleo e das exportacións destes. Nesta etapa poderiamos situar o verdadeiro gran salto no uso e consumo de recursos enerxéticos en Galiza respecto ao vivido nas etapas anteriores.

- Anos 70 e 80: ten lugar a explotación acelerada do carbón galego. Nestes anos tamén se produce un salto no consumo interno de electricidade, sobre todo para usos industriais.

- Século XXI: asistimos ao esgotamento do carbón autóctono e, en paralelo, a un aumento nas importacións de carbón e de gas natural. Comeza a haber unha expansión no uso doutras fontes renovábeis como a eólica, que se vai igualando en importancia á hidráulica. Estes cambios non conseguen mudar a base fósil do sistema enerxético galego nin reducir a dependencia enerxética. 


\section{REFERENCIAS BIBLIOGRÁFICAS}

Bartolomé Rodríguez, I. (2007): La industria eléctrica en España (1890-1936). Estudios de Historia Económica, no 50, Madrid, Banco de España.

CARMONA BADÍA, Xoán (2016): La Sociedad Gallega de Electricidad y la formación del sistema eléctrico galego (1900-1955), Barcelona, Fundación Gas Natural Fenosa.

Carreras, A. / X. TAFunell (coords.) (2005): Estadísticas históricas de España: siglos XIX-XX, Bilbao, Fundación BBVA.

Comisión para el Estudio de NeCesidades y Recursos Energéticos (1961): La Energía en España: evolución y perspectivas 1945-1975, Madrid, Ministerio de Industria.

CONSEllería De Industria E ENerXía (1984): El balance enerxético gallego. Producción y consumo sectorial de energía, Santiago de Compostela, Xunta de Galicia.

Consellería de Industria, Comercio e Turismo (1988): Balance Enerxético Galego, Santiago de Compostela, Xunta de Galicia.

GESTENGA (1993): Estatística Enerxética de Galicia, 1992, Santiago de Compostela, Gestenga / Consellería de Innovación, Industria e Comercio.

Martínez, A. / J. Mirás Araújo e E. Lindoso Tato (coords.) (2009): La industria del gas en Galicia: del alumbrado por gas al siglo XXI, 1850-2005, Barcelona, Fundación Gas Natural Fenosa.

Ministerio de Industria, COMERCio y TURISMo (diversos anos): Estadistica de la Industria de la Energía Eléctrica, Madrid.

INEGA (2001): Balance Enerxético de Galicia 2000, Santiago de Compostela, Xunta de Galicia.

INEGA (2003a): Balance Enerxético de Galicia 2001, Santiago de Compostela, Xunta de Galicia.

INEGA (2003b): Balance Enerxético de Galicia 2002, Santiago de Compostela, Xunta de Galicia.

INEGA (2004): Balance Enerxético de Galicia 2003, Santiago de Compostela, Xunta de Galicia.

INEGA (2006): Balance Enerxético de Galicia 2004, Santiago de Compostela, Xunta de Galicia.

INEGA (2007): Balance Enerxético de Galicia 2005, Santiago de Compostela, Xunta de Galicia.

INEGA (2008): Balance Enerxético de Galicia 2006, Santiago de Compostela, Xunta de Galicia.

INEGA (2010a): Balance Enerxético de Galicia 2007, Santiago de Compostela, Xunta de Galicia.

INEGA (2010b): Balance Enerxético de Galicia 2008, Santiago de Compostela, Xunta de Galicia.

INEGA (2011): Balance Enerxético de Galicia 2009, Santiago de Compostela, Xunta de Galicia.

INEGA (2012): Balance Enerxético de Galicia 2010, Santiago de Compostela, Xunta de Galicia.

INEGA (2013): Balance Enerxético de Galicia 2011, Santiago de Compostela, Xunta de Galicia.

INEGA (2014): Balance Enerxético de Galicia 2012, Santiago de Compostela, Xunta de Galicia.

INEGA (2017a): Balance Enerxético de Galicia 2013, Santiago de Compostela, Xunta de Galicia.

INEGA (2017b): Balance Enerxético de Galicia 2014, Santiago de Compostela, Xunta de Galicia.

INEGA (2017c): Balance Enerxético de Galicia 2015, Santiago de Compostela, Xunta de Galicia.

Sequeiros Tizón, J. (1986): El desarollo industrial en Galicia, Santiago de Compostela, Universidade de Santiago de Compostela. 